\title{
Retraction Note: Application of remote sensing and GIS technology in urban ecological environment investigation
}

\author{
Qiang Liu ${ }^{1}$
}

Published online: 6 December 2021

C) Saudi Society for Geosciences 2021

Retraction Note to: Arabian Journal of Geosciences (2021) 14: 1743 https://doi.org/10.1007/s12517-021-08118-8

The Editor-in-Chief and the Publisher have retracted this article because the content of this article is nonsensical. The peer review process was not carried out in accordance with the Publisher's peer review policy. The author has not responded to correspondence regarding this retraction.

The original article can be found online at https://doi.org/10.1007/ s12517-021-08118-8.

Qiang Liu

tt0812222021@163.com

School of Architectural Engineering, Chengdu Vocational and Technical College of Industry, Chengdu 610218,

Sichuan, China 